\title{
Modestobacter caceresii sp. nov., novel actinobacteria with an insight into their adaptive mechanisms for survival in extreme hyper-arid Atacama Desert soils
}

\author{
Kanungnid Busarakam ${ }^{\mathrm{a}}$, Alan T. Bull ${ }^{\mathrm{b}}$, Martha E. Trujillo ${ }^{\mathrm{c}}$, Raul Riesco ${ }^{\mathrm{c}}$, Vartul Sangal ${ }^{\mathrm{d}}$, \\ Gilles P. van Wezel ${ }^{\mathrm{e}}$, Michael Goodfellow ${ }^{\mathrm{a}, *}$ \\ a School of Biology, Newcastle University, Newcastle upon Tyne NE1 7RU, UK \\ ${ }^{\mathrm{b}}$ School of Biosciences, University of Kent, Canterbury CT2 7NJ, UK \\ c Departamento de Microbiología y Genética, Universidad de Salamanca, Campus Miguel de Unamuno, 37007 Salamanca, Spain \\ d Faculty of Health and Life Sciences, Northumbria University, Newcastle upon Tyne NE1 8ST, UK \\ e Molecular Biotechnology, Institute of Pathology, Leiden University, P.O. Box 9505230 RA Leiden. The Netherlands
}

\section{A R T I C L E I N F O}

\section{Article history:}

Received 8 December 2015

Received in revised form 16 March 2016

Accepted 18 March 2016

\section{Keywords:}

Modestobacter caceserii

Polyphasic taxonomy

Whole genome sequence

Hyper-arid Atacama Desert soil

Average nucleotide identity

Average amino acid identity

\begin{abstract}
A B S T R A C T
A polyphasic study was designed to determine the taxonomic provenance of three Modestobacter strains isolated from an extreme hyper-arid Atacama Desert soil. The strains, isolates KNN 45-1a, KNN 45-2b and KNN 45-3b, were shown to have chemotaxonomic and morphological properties in line with their classification in the genus Modestobacter. The isolates had identical 16S rRNA gene sequences and formed a branch in the Modestobacter gene tree that was most closely related to the type strain of Modestobacter marinus (99.6\% similarity). All three isolates were distinguished readily from Modestobacter type strains by a broad range of phenotypic properties, by qualitative and quantitative differences in fatty acid profiles and by BOX fingerprint patterns. The whole genome sequence of isolate KNN $45-2 b^{\mathrm{T}}$ showed $89.3 \%$ average nucleotide identity, 90.1\% (SD: 10.97\%) average amino acid identity and a digital DNA-DNA hybridization value of $42.4 \pm 3.1$ against the genome sequence of $M$. marinus DSM $45201^{\mathrm{T}}$, values consistent with its assignment to a separate species. On the basis of all of these data, it is proposed that the isolates be assigned to the genus Modestobacter as Modestobacter caceresii sp. nov. with isolate KNN $45-2 b^{\mathrm{T}}\left(\right.$ CECT $\left.9023^{\mathrm{T}}=\mathrm{DSM} 101691^{\mathrm{T}}\right)$ as the type strain. Analysis of the whole-genome sequence of $M$. caceresii $\mathrm{KNN} 45-2 \mathrm{~b}^{\mathrm{T}}$, with 4683 open reading frames and a genome size of $\backsim 4.96 \mathrm{Mb}$, revealed the presence of genes and gene-clusters that encode for properties relevant to its adaptability to harsh environmental conditions prevalent in extreme hyper arid Atacama Desert soils.
\end{abstract}

(c) 2016 Published by Elsevier GmbH.

\section{Introduction}

The genus Modestobacter [37] belongs to the family Geodermatophilaceae [41,42] of the order Geodermatophilales [59] which is a member of the class Actinobacteria [63]. Members of the

\footnotetext{
The GenBank EMBL/DDBJ accession numbers for the 16S rRNA gene sequences of Modestobacter caceserii isolates KNN 45-1a, KNN 45-2 ${ }^{\mathrm{T}}$ and KNN 45-3b are LN898186, LN898173 and LN898185, respectively. The partial gyrB gene sequences of isolates KNN45-1a, KNN 45-3b and the type strains of M. lapidis, M. marinus, M. multiseptatus, M. muralis, M. roseus and M. versicolor are LN898184, LN898183, LN898182, LN898181, LN898179, LN898180, LN898178 and LN898177, respectively. The whole-genome sequence number of $M$. caceserii $\mathrm{KNN} 45-2 \mathrm{~b}^{\mathrm{T}}$ is JPMX00000000.

* Corresponding author. Tel.: +440191208 7706

E-mail address: m.goodfellow@ncl.ac.uk (M. Goodfellow).
}

genus are currently recognised by a combination of chemotaxonomic, morphological and physiological properties [43,69]. They are aerobic, Gram-positive, non-spore-forming, heterotrophic actinobacteria which form rod- and coccoid-shaped elements which tend to remain aggregated and have a tendency to form multiseptate filaments and an ability to grow on oligotrophic media; the wall peptidoglycan contains meso-diaminopimelic acid, the major fatty acid is iso- $\mathrm{C}_{16: 0}$, the predominant respiratory quinone is tetrahydrogenated menaquinone with nine isoprene units (MK-9 $\left[\mathrm{H}_{4}\right]$ ) and the major polar lipids include diphosphatidylglycerol, phosphatidylethanolamine and phosphatidylinositol.

The genus Modestobacter currently encompasses six species, Modestobacter multiseptatus [37], the type species, Modestobacter lapidis [69], Modestobacter marinus [75], Modestobacter muralis [69], Modestobacter roseus [48] and Modestobacter versicolor [50] which form a distinct clade in the Geodermatophilaceae 16S rRNA gene 
tree. The small number of Modestobacter strains assigned to these species were isolated from markedly different ecosystems [69] though there is evidence that members of the genus are associated with extreme biomes, including regoliths and desert soils and with the surfaces of rocks and ancient monuments [19,44,45,70]. The presence of Modestobacter strains in such hostile environments may be partly due to their ability to form black pigments [12], melanin-like pigments which may prove to be a source of sun screens.

To date, Modestobacter strains have not been isolated from Atacama Desert soil. Members of the genus have been considered to access trace carbon sources on stone surfaces that are characterized by low organic carbon availability [12] while M. marinus strain BC501 has been reported to be highly resistant to gamma and high energy UV radiation [19].

Normand et al. [44] found that the 5.6 Mb genome of this strain contained several genes in multiple copies, such as coxSML (carbon monoxide dehydrogenase), katA (manganese-containing catalase) and $\operatorname{trwC}$ (conjugative relaxase) and $u v r A C D$ (UV resistance). The analysis of the proteome of isolate BC501 has provided additional insight into how Modestobacter strains cope with stressful environmental conditions [61].

The present study was designed to establish the taxonomic status of three Modestobacter strains isolated from an extreme hyper-arid Atacama Desert soil. The isolates, strains KNN 45-1a, KNN 45-2 $\mathrm{b}^{\mathrm{T}}$ and KNN 45-3b, were compared with the type strains of the six validly published Modestobacter species using a range of genotypic and phenotypic properties shown to be of value in the circumscription of Modestobacter species [69]. The strains were found to form a novel species of Modestobacter; the name proposed for this species is Modestobacter caceresii with isolate KNN 45-2b as the type strain. Analysis of the whole-genome sequence generated for this strain provided an insight into how the organism has adapted to harsh environmental conditions prevalent in extreme hyper-arid Atacama Desert soils.

\section{Materials and methods}

\section{Isolation of strains}

Modestobacter strains were recovered from an extreme hyperarid soil sample collected from the Yungay core region of the Atacama Desert (24 06' 18.6" S/70 01 55.6" W) using Gause’s No. 1 agar [76] and humic acid-vitamin agar [21]; these media were supplemented with actidione $\left(25 \mu \mathrm{g} \mathrm{ml}^{-1}\right)$ and in the case of the humic acid agar with nalidixic acid $\left(10 \mu \mathrm{g} \mathrm{ml}^{-1}\right)$. Aliquots $(100 \mu \mathrm{l})$ of a $10^{-1}$ suspension of the soil prepared in $1 / 4$ strength Ringer's solution (Oxoid) were spread over the plates of each of the isolation media which had been dried for $15 \mathrm{~min}$ at room temperature prior to inoculation, as recommended by Vickers and Williams [72]. After incubation at $28^{\circ} \mathrm{C}$ for 3 weeks, the presumptive Modestobacter isolates were counted and expressed as the number of colony forming units (cfu) per gram dry weight soil.

\section{Test strains, maintenance and cultural conditions}

Three representative strains were taken from the isolation plates, isolate KNN 45-1a was from one of the Gause's No. 1 agar plates and isolates KNN 45-2 $\mathrm{b}^{\mathrm{T}}$ and KNN 45-3b from humic acid agar plates. The isolates together with M. lapidis MON $3.1^{\mathrm{T}}$, M. marinus DSM 45201 ${ }^{\mathrm{T}}, M$. multiseptatus DSM $44406^{\mathrm{T}}$ and $M$. muralis MDVD1 ${ }^{\mathrm{T}}, M$. roseus DSM $45764^{\mathrm{T}}$ and $M$. versicolor DSM $16678^{\mathrm{T}}$ were maintained on modified Bennett's agar slopes [23] at room temperature and as suspensions of cells in $20 \% \mathrm{v} / \mathrm{v}$ glycerol at $-20^{\circ} \mathrm{C}$ and $-80^{\circ} \mathrm{C}$. Biomass for the fatty acid and molecular systematic analyses carried out on the isolates was harvested from yeast extract-malt extract agar plates (International Streptomyces Project [ISP] medium 2; [62] that had been incubated at $28^{\circ} \mathrm{C}$ for 5 days; the biomass preparations were washed twice in distilled water and stored at $-20^{\circ} \mathrm{C}$. Biomass for the additional chemotaxonomic studies carried out on isolate KNN $45-2 b^{\mathrm{T}}$ was prepared in shake flasks ( 200 revolutions per minute) of ISP 2 broth after incubation for 14 days at $28^{\circ} \mathrm{C}$; cells were harvested by centrifugation, washed twice in distilled water and freeze-dried.

\section{Phylogenetic analyses}

Genomic DNA was extracted from isolates KNN 45-1a, KNN 45-2 $\mathrm{b}^{\mathrm{T}}$ and KNN 45-3b and PCR-mediated amplification of $16 \mathrm{~S}$ rRNA and gyrase B (gyrB) genes and direct sequencing of the purified PCR products realised following procedures described by Carro et al. [10]. The resultant 16S rRNA gene sequences (1390-1405 bp) were aligned using CLUSTAL X [66] against corresponding sequences of the Modestobacter type strains retrieved from the GenBank database using the EzTaxon-e server [26]. Phylogenetic trees were inferred using the maximum-likelihood [14], maximum-parsimony [16] and neighbour-joining [55] algorithms with 1000 bootstrap replicates [15] after removing the gaps and missing data from the nucleotide sequence alignment using the MEGA 6 software package [65]. The neighbour-joining and maximum-parsimony trees were obtained using the Max-mini branch-and-bound algorithm [47]. The phylogenetic position of the three isolates was established using representative sequences from members of the family Geodermatophilaceae.

Partial gyrB gene sequences of all of the Modestobacter type strains generated in this study were used to determine the potential value of this gene as a phylogenetic marker. All sequences (1043-1361 bp) were aligned and the corresponding phylogenetic trees were constructed as explained above for the 16S rRNA gene. In this analysis, Geodermatophilus obscurus DSM $43160^{\mathrm{T}}$ was used as an outgroup.

\section{BOX typing}

BOX-PCR fingerprinting profiles from genomic DNA extracted from the isolates and Modestobacter type strains were generated using the BOXAIR primer [71] and previously described experimental conditions [68]. Cluster analysis based on the Pearson moment correlation coefficient was carried out with the software Gel-Compar II (Applied Maths).

\section{Chemotaxonomy}

The isolates were examined for the presence of the isomers of diaminopimelic acid $\left(\mathrm{A}_{2} \mathrm{pm}\right)$ following the procedure described by Hasegawa et al. [20]. In turn, fatty acids extracted from the isolates were methylated, analysed using the protocol of the Sherlock Microbial Identification (MIDI) system, version 5 [57]; the resultant peaks were named using the SACTIN 6 database and the results compared with those of the Modestobacter type strains which had been examined under the same experimental conditions [69]. Using standard chromatographic procedures isolate KNN $45-2 b^{\mathrm{T}}$ was examined for the presence of diagnostic menaquinones and polar lipids [38] and whole-organism sugars [64].

\section{Cultural and morphological properties}

The isolates were examined for motility and micromorphological properties using procedures described by Trujillo et al. [69]. Cultural properties of the isolates were recorded on 
tryptone-yeast extract, yeast extract malt extract oatmeal, inorganic salts-starch, glycerol-asparagine, peptone-yeast extract-iron and tyrosine agar plates (ISP media 1-7; [62]) following incubation at $28^{\circ} \mathrm{C}$ for 14 days.

\section{Phenotypic properties}

The isolates were screened for a combination of biochemical, degradation and physiological properties shown to be of value in an earlier study of Modestobacter strains [69]. All of the tests were carried out in duplicate using a standard inoculum equivalent to 5.0 on the McFarland scale [39]. In addition, the ability of the isolates to grow in the presence of carbon dioxide as a sole carbon source was examined using a Thermo Forma Series II Water Jacket $\mathrm{CO}_{2}$ incubator and carbon utilisation agar plates (ISP medium 9; [62]) was determined following incubation at $28^{\circ} \mathrm{C}$ for 14 days.

Whole-genome sequencing of isolate KNN $45-2 b^{T}$ and genomic analyses

Isolate KNN $45-2 b^{T}$ was grown in tryptone soy broth supplemented with $10 \%$ sucrose-yeast extract-malt extract $(1 \%, v / v)$, $5 \mathrm{mM} \mathrm{MgCl} 2$ and $0.5 \%$ glycine at $30^{\circ} \mathrm{C}$ for $48 \mathrm{~h}$. Cells were spun down, and resuspended in $10 \mathrm{mM} \mathrm{NaCl}, 20 \mathrm{mM}$ Tris- $\mathrm{HCl}(\mathrm{pH} 8.0)$ and $1 \mathrm{mM}$ EDTA then incubated with lysozyme at $37^{\circ} \mathrm{C}$ for $1-30 \mathrm{~min}$ until they were lysed. SDS ( $0.5 \%$ final concentration) and proteinase $\mathrm{K}(40 \mu \mathrm{g})$ were added and the cell extract incubated at $50^{\circ} \mathrm{C}$ for $6 \mathrm{~h}$ when a standard phenol-chloroform extraction was carried out on the lysate. The $\mathrm{pH}$ of the extract was adjusted to 5.5 with $0.3 \mathrm{M}$ sodium acetate and DNA spooled with a glass rod following the addition of 2 volumes of $96 \%$ ethanol. After washing and drying the DNA was dissolved in TE buffer, DNA quality was verified by sal1 digestion and agarose gel electrophoresis.

The genome of strain KNN $45-2 b^{T}$ was sequenced on an Illumina platform (Service SX, Leiden, The Netherlands). The quality of the 100-nt pair end reads was verified using FastQC [1] and depending on the quality, reads were trimmed to various lengths at both ends. The trimmed reads were assembled using Velvet [77]. The genome was annotated using the RAST server [3] with default options. Predictions of gene clusters for natural products were performed using antiSMASH [35]. Protein sequences of genes belonging to cox and uvr gene clusters in M. marinus strain BC501 were BLAST searched in the genome of strain KNN $45-2 b^{T}$ on the SEED server using default settings [4].

A BLAST based average nucleotide identity (ANIb) of the genome of strain KNN 45-2 $\mathrm{b}^{\mathrm{T}}$ was calculated against the genome sequence of $M$. marinus DSM $45201^{\mathrm{T}}$ (Sangal and Goodfellow, unpublished data) using Jspecies [52]. A two-way average amino acid identity (AAI) was calculated using the protein sequences of these strains by an online resource from the K. Konstantinidis group (http:// enve-omics.ce.gatech.edu/aai/). The digital DNA-DNA hybridization $(\mathrm{dDDH})$ values between these genomes were calculated using the genome-to-genome distance calculator, GGDC $2.0[2,36]$.

\section{Results}

Isolation, enumeration, cultural and morphological properties and phylogeny

Small numbers of strains growing on the isolation plates were assigned to the genus Modestobacter as they formed characteristically round, slightly mucoid colonies that were initially orange to beige in colour but later turned black. The highest count, $6.0 \times 10^{-1} \mathrm{cfu} / \mathrm{g}$ dry weight soil, was recorded on the humic acid-vitamin agar plates. All of the isolates were shown to be

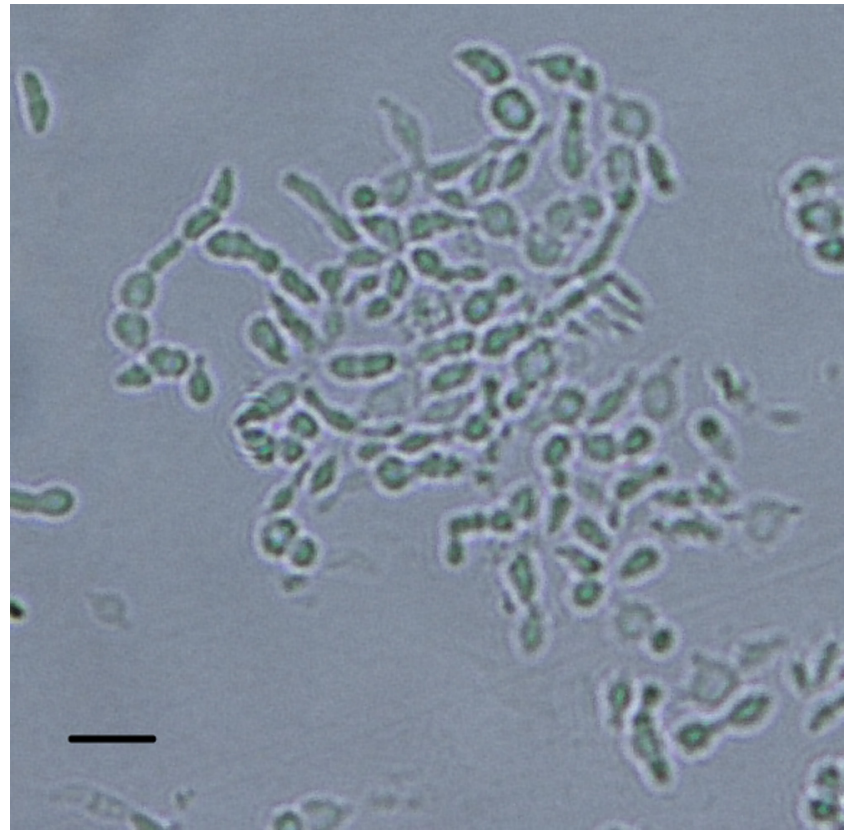

Fig. 1. Phase contrast image of strain KKNN $45-2 b^{T}$ grown on ISP 2 agar at $28^{\circ} \mathrm{C}$ for 3 days. Bar, $5 \mu \mathrm{m}$.

Gram-stain-positive, non-motile and formed short-rod and coccoid shaped cells that had a tendency to remain aggregated (Fig. 1). Colonies were olive to yellowish in colour, but turned black on prolonged incubation. The isolates and the Modestobacter type strains were found to grow well on most of the ISP media producing pigments that ranged from yellowish white to black (Table 1). The colonies were flat, round and mucoid with entire margins.

The isolates were shown to have identical 16S rRNA gene sequences, which, when compared with corresponding sequences of the Modestobacter type strains showed that they formed a distinct lineage within the evolutionary radiation of the genus Modestobacter, one that was supported by the neighbour-joining, maximum-likelihood and maximum-parsimony algorithms and by an $86 \%$ bootstrap value (Fig. 2 ). The strains formed a well delineated branch in the Modestobacter 16S rRNA gene tree together with the type strains of $M$. marinus and $M$. roseus, a relationship supported by a $96 \%$ bootstrap value and by all three tree-making algorithms. They were shown to be most closely related to the type strain of $M$. marinus sharing a 99.6\% 16S rRNA gene similarity with the latter, a

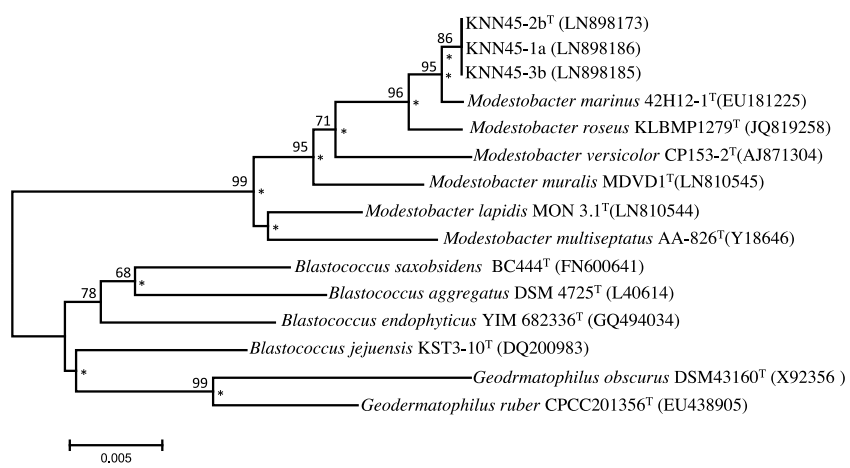

Fig. 2. Neighbour-joining phylogenetic tree based on $16 \mathrm{~S}$ rRNA gene sequences of isolates KNN 45-1a, KNN 45-2 ${ }^{\mathrm{T}}$ and $\mathrm{KNN} 45-3 \mathrm{~b}$ and representative type strains of the family Geodermatophilaceae. Asterisks indicate that the corresponding branches were recovered in the maximum-likelihood and maximum-parsimony trees. Only bootstrap values above $50 \%$ are shown. Bar, 0.005 substitutions per nucleotide position. 
Table 1

Growth and cultural characteristics of isolates and Modestobacter type strains on ISP media after incubation for 14 days at $28{ }^{\circ} \mathrm{C}$.

\begin{tabular}{|c|c|c|c|}
\hline Media & Growth & Colony colour & Diffusible pigment \\
\hline Glycerol-asparagine agar (ISP5) & ++ & Olive-Black ${ }^{\mathrm{a}}$ & None \\
\hline Inorganic salts-starch agar (ISP 4) & + & Yellowish-white & None \\
\hline Oatmeal agar (ISP 3) & +++ & Olive-black & None \\
\hline Peptone-yeast extract -iron agar (ISP 6) & +++ & Black/orange ${ }^{\mathrm{b}}$ & None/light yellow ${ }^{\mathrm{b}}$ \\
\hline Tryptone-yeast extract agar (ISP 1) & +++ & Yellowish-white & None \\
\hline Tyrosone agar (ISP 7) & +++ & Yellowish-white & None/light yellow ${ }^{\mathrm{b}}$ \\
\hline Yeast extract-malt extract agar (ISP 2) & ++++ & White yellow-black & None/light yellow ${ }^{b}$ \\
\hline
\end{tabular}

Key: ++++, abundant growth; +++, very good growth; ++, good growth; +, poor growth.

a The $M$. lapidis and M. muralis colonies were orange-black and brown-black, respectively.

b Results for isolates KNN 45-1a, KNN 45-2b ${ }^{\mathrm{T}}$ and KNN 45-3b and for the type strain of $M$. versicolor.
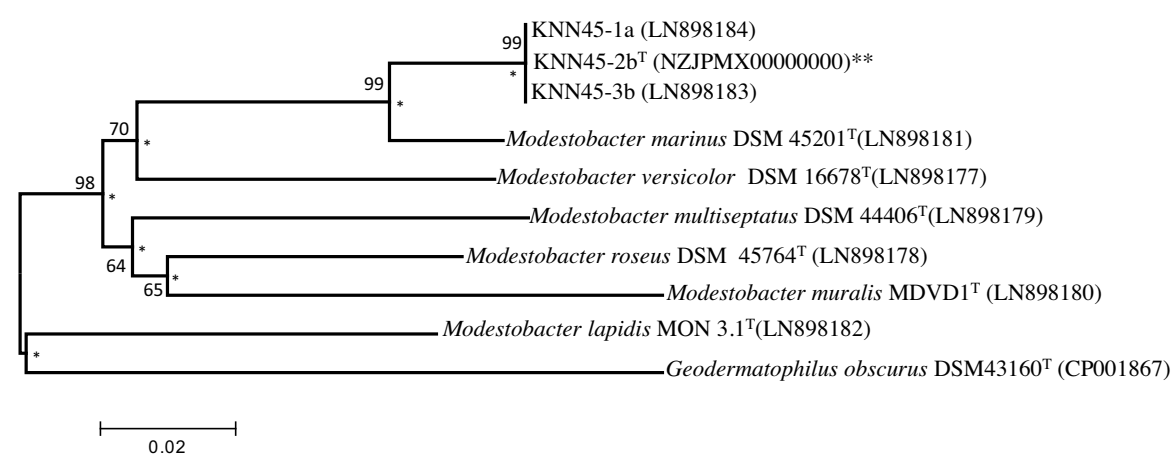

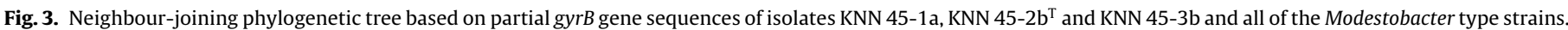

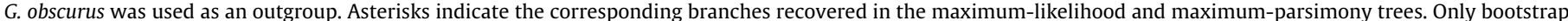

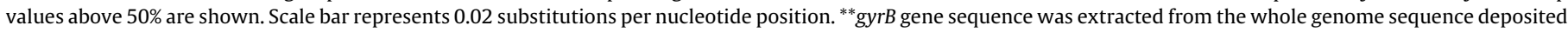
in public databases under accession number JPMX01000080 (Region: 2895-4931).

value that corresponds to 5 nucleotide (nt) differences at between 1387 and 1403 locations; the corresponding figures between the isolates and the $M$. roseus type strain were 99.4\% 16S rRNA gene sequence similarity and $9 \mathrm{nt}$ differences at between 1385 and 1409 sites.

The three isolates were recovered as a well-defined cluster in the gyrB gene tree with $M$. marinus as the most closely related species, a result supported by a bootstrap value of $99 \%$ (Fig. 3). Sequence similarities between the isolates were identical while a value of $96.4 \%$ was obtained between them and the type strain of $M$. marinus. The same tree topology was obtained when the different algorithms used for the 16S rRNA gene sequence analyses were applied. Overall, the Modestobacter species had sequence similarities between $87.8 \%$ and $91.1 \%$ and were well separated; the gyrB gene phylogeny showed better resolution than the corresponding 16S rRNA phylogeny.

BOX-PCR profiles of the isolates and selected reference Modestobacter type strains clearly showed the diversity of their genetic profiles (Fig. S1). The isolates have very similar banding patterns which sharply distinguish them from the reference strains, notably from the type strain of $M$. marinus.

\section{Chemotaxonomy}

The three isolates were found to contain meso- $\mathrm{A}_{2} \mathrm{~m}$ as the diamino acid, iso- $\mathrm{C}_{16: 0}$ as the predominant fatty acid, but lacked mycolic acids. The fatty acid profiles of the isolates were seen to show qualitative and quantitative differences when compared with corresponding profiles of the Modestobacter type strains, as exemplified by the presence of predominant amounts of $\mathrm{C}_{17: 0}$ and iso- $\mathrm{C}_{15: 0}$ in the type strains of $M$. marinus and M. multiseptatus, respectively (Table 2 ). Isolate $\mathrm{KNN} 45-2 \mathrm{~b}^{\mathrm{T}}$ was found to contain tetrahydrogenated menaquinone as the sole isoprenologue, whole-cell hydrolysates rich in arabinose, glucose, ribose and rhamnose, and diphosphatidylglycerol, phosphatidylethanolamine (taxonomically significant component), phosphatidylglycerol, phosphatidylinositol, phosphatidylinositol mannoside, and three unidentified lipids (Fig. S2).

\section{Phenotypic tests}

Duplicated strains of KNN 45-1a, KNN 45-2b ${ }^{\mathrm{T}}$ and KNN 45-3b were found to give identical results for all of the phenotypic tests. The isolates and the Modestobacter type strains were shown to grow at $20^{\circ} \mathrm{C}$ and $28^{\circ} \mathrm{C}$, at $\mathrm{pH} 7.0$ and $\mathrm{pH} 8.0$, produce acid phosphatase, esterase (C4), leucine arylamidase, naphthol-AS-B1 phosphohydrolase and valine arylamidase (API tests), reduce nitrate to nitrite, hydrolyse urea, use acetoacetic acid and dextrin as sole carbon sources and grow in the presence of fusidic acid, minocycline and potassium tellurite (Biolog GENIII microplates). Scant growth was detected in the presence of $5 \% \mathrm{CO}_{2}$ as the sole carbon source. In contrast, none of the strains were found to grow at $40^{\circ} \mathrm{C}$, at $\mathrm{pH} 4,10$ or 11 , to produce $\alpha$-fucosidase, $\alpha$ - or $\beta$-galactosidases (API ZYM tests) or to assimilate $\alpha$-amino-butyric acid, formic acid, $\alpha$-methyl-Dglucoside, glycyl-proline or methyl pyruvate as sole carbon sources (Biolog GEN III microplates).

The remaining phenotypic tests were found to distinguish the three isolates from the Modestobacter type strains (Table 3) which had been examined using the same media, methods and cultivation conditions [69]. In particular, the isolates were separated from the type strain of $M$. marinus, as exemplified by their ability to produce $\alpha$-chymotrypsin and esterase lipase (C8) (API ZYM tests), to assimilate acetic acid, gentiobiose, D-raffinose, D-serine, D-trehalose and D-turanose and grow in the presence of tetrazolium violet (Biolog GEN III microplates). 
Table 2

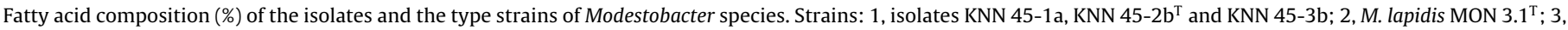

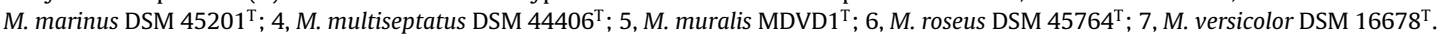

\begin{tabular}{|c|c|c|c|c|c|c|c|}
\hline Fatty acid & 1 & 2 & 3 & 4 & 5 & 6 & 7 \\
\hline$C_{12: 0}$ & $0.2-0.7$ & - & - & - & - & - & - \\
\hline iso- $\mathrm{C}_{13: 0}$ & - & 0.1 & - & - & - & - & - \\
\hline$C_{13: 0}$ & - & - & 0.4 & - & - & - & - \\
\hline iso- $\mathrm{C}_{14: 0}$ & $1.6-1.9$ & 2.1 & 1.3 & 1.1 & 1.4 & 2.4 & 1.0 \\
\hline$C_{14: 0}$ & $0.3-0.9$ & 2.1 & 1.0 & 0.4 & 0.9 & 0.3 & 0.3 \\
\hline iso- $\mathrm{C}_{15: 1} \mathrm{G}$ & $0.7-1.5$ & 5.3 & 0.7 & 1.7 & - & - & 2.8 \\
\hline iso- $\mathrm{C}_{15: 0}$ & $2.9-7.4$ & 17.4 & 9.7 & 21.5 & 8.2 & 11.0 & 19.9 \\
\hline anteiso- $\mathrm{C}_{15: 0}$ & $0.6-1.0$ & 2.5 & 4.2 & 3.7 & 1.5 & 4.5 & 2.8 \\
\hline $\mathrm{C}_{15: 1 \mathrm{~B}}$ & $0.3-0.4$ & 1.2 & 0.7 & - & - & - & - \\
\hline $\mathrm{C}_{15: 0}$ & $0.6-1.7$ & 2.3 & 5.6 & 1.3 & 3.9 & 1.3 & 0.7 \\
\hline iso- $\mathrm{C}_{16: 1} \mathrm{H}$ & $1.3-9.4$ & 3.6 & 0.7 & 0.5 & - & 5.3 & - \\
\hline iso- $\mathrm{C}_{16: 0}$ & $22.6-39.1$ & 21.8 & 10.3 & 19.7 & 16.1 & 21.9 & 22.2 \\
\hline$C_{16: 1 \omega 9 c}$ & 7.3-11.1 & 10.0 & 3.2 & 1.0 & 3.6 & - & 1.3 \\
\hline$C_{16: 0}$ & $5.7-8.8$ & 7.6 & 11.2 & 3.8 & 8.3 & 7.2 & 3.2 \\
\hline 9-methyl $C_{16: 0}$ & $0.7-0.9$ & 0.5 & 0.3 & - & - & 1.2 & 2.0 \\
\hline anteiso- $\mathrm{C}_{17: 1 \mathrm{C}}$ & $0.2-0.4$ & 0.5 & 0.2 & 0.2 & - & - & 0.4 \\
\hline iso- $\mathrm{C}_{17: 0}$ & $0.9-3.1$ & 1.0 & 2.8 & 8.8 & 3.2 & 3.1 & 8.7 \\
\hline anteiso- $\mathrm{C}_{17: 0}$ & $0.7-1.4$ & 1.6 & 3.7 & 5.9 & 3.2 & 2.1 & 4.9 \\
\hline$C_{17: 1 \omega 9 c}$ & $8.5-13.8$ & 6.9 & 13.7 & 4.8 & 19.4 & 15.0 & 5.5 \\
\hline Cyclo $\mathrm{C}_{17: 0}$ & $0.7-2.5$ & 2.3 & 0.2 & - & - & 1.0 & - \\
\hline$C_{17: 0}$ & $1.2-5.3$ & 1.5 & 20.0 & 8.6 & 17.2 & 9.6 & 4.8 \\
\hline 10 -methyl $C_{17: 0}$ & $0.8-2.0$ & 0.2 & - & 0.4 & 0.5 & 1.0 & 0.9 \\
\hline$C_{18: 3 \omega 6 c, 12,14 c}$ & $1.2-4.1$ & - & 1.3 & 0.9 & 1.0 & - & 1.0 \\
\hline iso- $\mathrm{C}_{18: 0}$ & $0.3-0.5$ & - & - & 0.5 & - & - & 0.4 \\
\hline$C_{18: 1 \omega 9 c}$ & $4.4-10.2$ & 3.9 & 2.1 & 5.5 & 5.4 & 2.1 & 9.8 \\
\hline $\mathrm{C}_{18: 0}$ & $0.6-3.0$ & 0.8 & 3.7 & 6.6 & 2.8 & 0.6 & 3.9 \\
\hline iso- $\mathrm{C}_{17: 0} \mathrm{OH}$ & $1.6-2.1$ & 2.7 & 2.6 & 2.8 & 3.2 & - & 0.9 \\
\hline$C_{16: 1 \omega 7 c} / C_{17: 1 \omega 6 c}$ & - & - & - & - & - & 8.4 & - \\
\hline$C_{18: 1 \omega 7 c} / C_{18: 1 \omega 9 c} / C_{18: 1 \omega 12 t}$ & $0-0.5$ & 0.1 & - & - & - & 0.4 & - \\
\hline iso- $C_{17: 0 ~} \omega 9 \mathrm{c} / 10$-methyl $C_{16: 0}$ & $0-0.5$ & 1.0 & 0.4 & 0.8 & 1.0 & 1.5 & 1.3 \\
\hline
\end{tabular}

Genomic analyses resolving the taxonomic status of KNN45-2 $b^{T}$

The whole genome sequence of strain KNN45-2b $\mathrm{b}^{\mathrm{T}}$ was compared to that of its nearest phylogenetic neighbour, namely $M$. marinus DSM 45201 ${ }^{\mathrm{T}}$ (Sangal and Goodfellow, unpublished data). ANIb values of $89.3 \%$ and $90.4 \%$ were observed when the genome sequence of KNN45-2 $\mathrm{b}^{\mathrm{T}}$ and M. marinus DSM $45201^{\mathrm{T}}$ were used as reference against one another, respectively. Similarly, an AAI value of $90.1 \%$ (SD: $11 \%$ ) was observed between these strains. The dDDH value was $42.4 \pm 3.1$ between isolate KNN45-2 $\mathrm{b}^{\mathrm{T}}$ and $M$. marinus DSM $45201^{\mathrm{T}}$, a value well below the recommended cut-off value of $70 \%$ for the assignment of strains to the same species [74]. These results provide further evidence that these strains belong to two different species.

\section{Detection of genes associated with stress responses}

The genome of isolate KNN $45-2 b^{T}$ was assembled into 140 contigs to give a total genome size of $\backsim 4.96 \mathrm{Mb}$ with an average GC content of $73.6 \mathrm{~mol} \%$. The genome sequence has been deposited at DDBJ/EMBL/GenBank under accession number JPMX00000000. The whole genome was annotated to include 4683 protein coding sequences and 50 RNA ( 47 tRNA) genes by the RAST pipeline.

The SEED analyses [4] of the KNN 45-2 $\mathrm{b}^{\mathrm{T}}$ genome identified 110 genes that are associated with stress responses, including $h r c A$ and grpE genes and the dnaK-J gene cluster involved in the heat shock response [29] and four genes encoding the CspA family of proteins that respond to cold shock (Supplementary Table 1; [12]). Multiple copies of bet genes ( 2 copies of betA, one copy of betB and two copies of betT) and two proU and one sox gene cluster involved in the uptake of choline and betaine and betaine biosynthesis are also present $[7,25,33,46,73]$. These metabolic activities contribute to the response against osmotic stress $[6,40]$. Two genes involved in carbon starvation were identified (fig|6666666.51110.peg.3264 and fig|6666666.51110.peg.1467) that encode a carbon storage regulator CsrA and carbon starvation protein A, respectively (Supplementary Table 1), CsrA is a global regulator involved in repression of multiple genes/pathways, including glycogen biosynthesis [53,54]. Carbon starvation protein A may help the strain to survive in low carbon habitats by activating peptide uptake $[31,49,58]$. Although the SEED analyses did not identify any genes associated with the response to desiccation stress, a number of genes involved in the biosynthesis and uptake of trehalose were scattered across the genome; trehalose has been linked with tolerance to heat and desiccation in bacteria [51].

The BLAST search of the genes involved in UV resistance in M. marinus strain BC501 revealed the presence of two copies of $u v r A$, one $u v r B$ and three copies of $u v r D$ genes in strain KNN $45-2 b^{\mathrm{T}}$ (Supplementary Table 2), the uvrC gene of strain BC501 showed partial similarity with a gene in strain KNN $45-2 b^{T}$. The KNN $45-2 b^{\mathrm{T}}$ genome also contained a recO gene and three copies of recQ DNA helicase that are known to be involved in stabilizing the genome [22,34]. The BLAST searches also revealed the presence of two coxGLSM gene clusters, an additional cluster of coxLSM, as well as coxD and coxE genes (Supplementary Table 2). The coxGLSM cluster encodes different subunits of carbon monoxide (CO) dehydrogenase that contain domains for molybdopterin, Fe-S and FAD-binding. Carbon monoxide dehydrogenases enable chemolithoautotrophic lifestyles in bacteria through utilization of $\mathrm{CO}$ as a carbon and energy source [30].

\section{Biosynthetic gene clusters for secondary metabolites}

Antibiotics and Secondary Metabolite Analysis Shell (antiSMASH version 3.0.4; [35]) identified a siderophore gene cluster that is predicted to encode desferrioxamine B. Four of the five biosynthetic genes of this gene cluster show significant homology with the desferrioxamine B gene cluster in Streptomyces coelicolor strain A3(2) [5,67]. In addition, five other putative gene clusters were identified in the KNN $45-2 b^{T}$ genome, including 
Table 3

Phenotypic properties that distinguish isolates KNN 45-1a, KNN 45-2 $\mathrm{b}^{\mathrm{T}}$ and KNN 45-3b from the type strains of Modestobacter species.

\begin{tabular}{|c|c|c|c|c|c|c|c|}
\hline & $\begin{array}{l}\text { Isolates: KNN } \\
45-1 \mathrm{a}, \mathrm{KNN} 45-2^{\mathrm{T}} \\
\text { and } 45-3 \mathrm{~b}\end{array}$ & $\begin{array}{l}\text { M. lapidis } \\
\text { MON } 3.1^{\mathrm{T}}\end{array}$ & $\begin{array}{l}\text { M. marinus } \\
\text { DSM } 45201^{\mathrm{T}}\end{array}$ & $\begin{array}{l}\text { M. } \\
\text { multiseptatus } \\
\text { DSM } 44406^{\mathrm{T}}\end{array}$ & $\begin{array}{l}\text { M. muralis } \\
\text { MDVD1 }^{\mathrm{T}}\end{array}$ & $\begin{array}{l}\text { M. roseus } \\
\text { DSM } 45764^{\mathrm{T}}\end{array}$ & $\begin{array}{l}\text { M. versicolor } \\
\text { DSM } 16678^{\mathrm{T}}\end{array}$ \\
\hline \multicolumn{8}{|l|}{ API-ZYM tests } \\
\hline Alkaline phosphatase & + & - & + & - & + & + & + \\
\hline$\alpha$-Chymotrypsin & + & + & - & + & - & + & + \\
\hline Cysteine arylamidase & + & + & + & + & + & + & - \\
\hline Esterase lipase (C8) & + & - & - & - & - & + & + \\
\hline$\alpha$-Glucosidase & - & + & - & + & - & - & - \\
\hline$\beta$-Glucosidase & - & + & - & - & - & - & - \\
\hline Trypsin & - & - & - & - & - & + & - \\
\hline \multicolumn{8}{|l|}{ BIOLOG GEN III microplate tests } \\
\hline \multicolumn{8}{|l|}{ a. Assimilation of: } \\
\hline Acetic acid, D-turanose & + & + & - & + & - & + & - \\
\hline $\begin{array}{l}\text { N-Acetyl- } \beta \text {-D-glucosamine, N-acetyl- } \beta \text {-D-mannose, } \\
\text { D-fructose, D-lactose, L-mannose }\end{array}$ & + & - & - & + & - & + & - \\
\hline $\mathrm{N}$-acetyl-muramic acid, L-lactic acid & + & - & - & + & - & + & + \\
\hline L-Alanine & + & - & - & + & - & + & + \\
\hline D-Arabitol, D-fucose, L-rhamnose, D-saccharic acid & - & - & - & + & - & - & + \\
\hline L-Arginine, $\alpha$-keto-butyric acid, L-histidine, myo-inositol & - & - & - & + & - & - & + \\
\hline D-Aspartic acid, D-fructose- $6 \mathrm{PO}_{4}$ & + & + & - & + & - & + & + \\
\hline L-Aspartic acid & + & + & - & + & - & - & + \\
\hline$\alpha$-Hydroxy-butyric acid, glucuronamide & - & - & - & - & + & - & + \\
\hline $\begin{array}{l}\beta \text {-Hydroxy-DL-butyric acid, D-saccharic acid, } \\
\text { b-Hydroxy-DL-butyric acid }\end{array}$ & - & - & - & + & - & + & - \\
\hline D-Cellobiose & - & + & - & + & - & + & - \\
\hline Citric acid, D-fucose, D-sorbitol & - & + & - & - & - & - & - \\
\hline D-Galactose, D-mannose & - & - & + & + & + & - & - \\
\hline D-Galacturonic acid, $\alpha$-D-glucose, D-pectin & + & + & - & - & + & + & + \\
\hline L-Galacturonic acid, glucuronamide & - & + & - & - & - & - & + \\
\hline Gelatin & - & + & - & - & + & - & - \\
\hline Gentiobiose & + & + & - & - & - & - & + \\
\hline D-Gluconic acid, sodium bromide & - & - & + & + & + & - & + \\
\hline$\alpha$-D-Glucose, D-pectin & - & - & + & - & + & + & + \\
\hline$\alpha$-keto-Glutaric acid & - & + & + & + & - & - & - \\
\hline 3-Methyl-glucose & - & - & - & - & + & - & - \\
\hline D-Glucuronic acid & - & - & + & - & - & - & + \\
\hline L-Glutamic acid & - & - & - & + & + & - & + \\
\hline Glycerol & - & - & - & + & - & + & + \\
\hline Inosine & + & + & + & + & - & - & + \\
\hline D-Lactic acid methyl ester & + & - & - & - & + & + & + \\
\hline D-Malic acid & - & + & + & - & + & - & + \\
\hline L-Malic acid, quinic acid & - & + & - & + & + & - & + \\
\hline D-Maltose & - & + & - & + & - & - & + \\
\hline Mucic acid & - & - & - & + & + & + & - \\
\hline D-Glucose- $\mathrm{PO}_{4}$, D-melibiose & + & + & - & - & - & + & + \\
\hline $\begin{array}{l}\text { p-Hydroxy-phenylacetic acid, bromo-succinic acid, } \\
\text { D-sorbitol }\end{array}$ & - & + & - & - & - & - & - \\
\hline Propionic acid, L-pyroglutamic acid & - & + & - & - & + & + & - \\
\hline D-Raffinose, D-trehalose & + & - & + & + & - & + & - \\
\hline D-Salicin & - & - & - & + & - & - & + \\
\hline D-Serine & + & + & - & - & - & + & + \\
\hline Stachyose & - & - & - & - & - & + & - \\
\hline Sodium butyrate & + & - & + & - & + & - & + \\
\hline Sodium lactate & - & + & + & + & + & - & + \\
\hline D-Sucrose & + & + & - & + & - & + & + \\
\hline D-Trehalose & + & + & - & + & - & + & - \\
\hline \multicolumn{8}{|l|}{ b. Growth in presence of inhibitory compounds } \\
\hline Aztreonam & + & - & + & + & + & + & + \\
\hline Guanidine $\mathrm{HCl}$ & + & - & - & - & + & - & + \\
\hline Lincomycin & + & + & + & - & + & - & + \\
\hline Lithium chloride & + & + & + & + & + & + & - \\
\hline Nalidixic acid & + & + & + & + & + & - & + \\
\hline Niaproof 4 & - & - & - & + & + & + & + \\
\hline Rifamycin SV & - & - & + & + & + & + & + \\
\hline Tetrazolium blue & - & + & - & + & - & - & + \\
\hline Tetrazolium violet & + & + & - & + & - & + & + \\
\hline Troleandomycin & - & + & - & + & + & - & + \\
\hline Vancomycin & + & + & - & + & + & - & + \\
\hline Growth at pH 5.0 & + & - & + & + & + & - & + \\
\hline Growth in presence of $8 \% \mathrm{w} / \mathrm{v} \mathrm{NaCl}$ & - & - & + & + & + & - & + \\
\hline \multicolumn{8}{|l|}{ Resistance to antibiotics $\left(\mu \mathrm{g} \mathrm{ml}^{-1}\right)$ : } \\
\hline Ampicillin (4), Cephaloridine (2), & - & - & + & - & - & - & + \\
\hline Ciprofloxacin (2) & - & - & + & - & - & + & + \\
\hline Lincomycin (3) & - & - & - & - & + & - & + \\
\hline
\end{tabular}

Key: +, positive; - , negative. 
one type II polyketide, one type III polyketide and two terpene biosynthetic clusters. One gene cluster was not assigned to any functional category. Although this strain was isolated from an extreme environment, biosynthetic gene clusters for the synthesis of antibiotics or other special biomolecules were not identified. However, antiSMASH may have limited capabilities to detect all of the biosynthetic gene clusters in the genome, as observed for Streptomyces leeuwenhoekii $\mathrm{C} 34^{\mathrm{T}}$ where the hygromycin A gene cluster was not identified by antiSMASH [8,17].

\section{Discussion}

The three representative strains taken from the isolation plates were found to share morphological and phenotypic properties and fatty acid profiles consistent with their classification in the genus Modestobacter [43,69], a point underlined by the menaquinone, whole cell sugar and lipid composition of isolate KNN $45-2 b^{T}$. In addition, the isolates formed a branch in the Modestobacter 16S rRNA and gyrB gene trees (Figs. 2 and 3) that were most closely related to the type strain of $M$. marinus but were distinguished readily from the latter based on fatty acid (Table 2) and BOX-PCR (Fig. S1) profiles and by a broad range of phenotypic properties (Table 3).

Whole genome sequence analyses such as ANI [27,28] and AAI between orthologous genes [60] are powerful and reliable tools for species delineation [56]. Genome-to-genome sequence comparison has also been widely used to delineate prokaryotic species and $\mathrm{dDDH}$ values found to highly correlate with genetic distances based on variations in 16S rRNA genes [2,56]. It was, therefore, encouraging that the ANIb, AAI and $\mathrm{dDDH}$ values between the genomes of isolate KNN45-2 $\mathrm{b}^{\mathrm{T}}$ and M. marinus DSM $45201^{\mathrm{T}}$ indicated that these strains clearly belong to distinct species within the genus Modestobacter.

It is evident from this broad-ranging polyphasic taxonomic study that isolates KNN 45-1a, KNN 45-2 $\mathrm{b}^{\mathrm{T}}$ and $45-3 \mathrm{~b}$ form a centre of taxonomic variation within the genus Modestobacter that merits recognition as a new species. It is proposed that these isolates be recognised as Modestobacter caseresii sp. nov.

Description of $M$. caceresii (ca.ce. res'.i.i. sp. nov.caceresii, named in honour of Luis Cáceres in recognition of his studies on relative humidity patterns and water availability in arid Atacama Desert soils.

Aerobic, Gram-stain-positive, non-motile actinobacteria which form short rods and coccoid-like elements and grow especially well on ISP 2 agar as black mucoid colonies. Grows from 20 to $37^{\circ} \mathrm{C}$, optimally $\backsim 28^{\circ} \mathrm{C}$, and from pH 5-9, optimally $\backsim \mathrm{pH} 7.5$ and in the presence of $8 \%(\mathrm{w} / \mathrm{v}) \mathrm{NaCl}$. Additional phenotypic properties are cited in the text and in Tables 1 and 3. The predominant fatty acid is iso- $\mathrm{C}_{16: 0}$. Other chemotaxonomic markers match those described for members of the genus Modestobacter. The $\mathrm{G}+\mathrm{C}$ content of the type strain is $72.5 \pm 1.0 \mathrm{~mol} \%$. Strain KNN $45-2 \mathrm{~b}^{\mathrm{T}}$ (CECT $9023^{\mathrm{T}}=\mathrm{DSM} 101691^{\mathrm{T}}$ ) was isolated from an extreme hyper-arid soil from the Yungay core region of the Atacama Desert in Chile. The GenBank accession number for the 16S rRNA gene sequence of isolate KNN $45-2 b^{\mathrm{T}}$ is LN898173 and that of its whole-genome sequence JPMX 00000000.

This first report of Modestobacter strains from Atacama Desert soil provides further evidence that members of this poorly studied genus are present in habitats characterised by low water and nutrient availability, high solar radiation and sharp variations in temperature $[9,12,13,45]$. Given this context, it is particularly interesting that genes and gene clusters identified in the genome of isolate KNN 45-2b $\mathrm{b}^{\mathrm{T}}$ encode for attributes relevant to its ability to counter harsh conditions found in extreme hyper-arid Atacama Desert soils, as witnessed by genes involved in responses to osmotic stress (bet $A-B$ genes and the sox gene cluster $[6,40]$ ), heat shock ( $h r c A$, grpE and dna K-J gene, [29]), cold shock (cspA family genes; [13]) and heat tolerance and desiccation (biosynthesis and uptake of trehalose [51]). The organism is also equipped to survive low nutrient conditions and the presence in the genome of multiple sox genes is consistent with a chemolithotrophic metabolism as the isolate has the capacity to use $\mathrm{CO}$ as a sole carbon and energy source $[11,30]$. It also has the potential to metabolise environmental proteins and peptides under starvation conditions as it has a gene that encodes for carbon starvation protein $\mathrm{A}$, this gene has been reported to activate peptide uptake during energy starvation thereby allowing bacteria to use alternative energy sources [49,58].

Microorganisms in Atacama Desert soils need strategies to survive high levels of UV radiation which can damage DNA by a number of photochemical reactions; nucleotide excision repair plays a key role in repairing damaged DNA $[18,24]$. Isolate KNN 45-2 ${ }^{\mathrm{T}}$ has the ability to protect and repair damage caused by UV radiation as it has genes that encode for Uvr ABCD proteins, excision proteins that have been reported in a number of bacteria [18]. Mutations in uvr $A B C$ genes have been shown to be associated with UV sensitivity in Rhodobacter sphaeroides [32].

\section{Conflict of interest}

The authors declare no conflicts of interest.

\section{Acknowledgements}

KB is grateful for a scholarship from The Royal Thai Government, ATB for support from The Royal Society (International Joint Programme Grant JP 100654), MG for an Emeritus Fellowship from The Leverhulme Trust and MET for a grant from the Universidad de Salamanca (Programa 1, 18KAZG/463AC01). The authors are also indebted to Dr. J.E.M. Stach (School of Biology, Newcastle University) for initial helpful advice on interpreting the genome of isolate KNN 45-2 ${ }^{\mathrm{T}}$.

\section{Appendix A. Supplementary data}

Supplementary data associated with this article can be found, in the online version, at http://dx.doi.org/10.1016/j.syapm.2016.03. 007.

\section{References}

[1] Andrews, S. 2010 Fast QC: a quality control tool for high throughput sequence data , Available on-line at: http://www.bioinformatics.babraham.ac. uk//projects/fastqc.

[2] Auch, A.F., von Jan, M., Klenk, H.-P., Goker, M. (2010) Digital DNA: DNA hybridization for microbial species delineation by means of genome-togenome comparison. Stand. Genom. Sci. 2, 117-134.

[3] Aziz, R.K., Bartels, D., Best, A.A., DeJongh, M., Disz, T., et al. (2008) The RAST server: rapid annotations using subsystems technology. BMC Genom. 9, 75.

[4] Aziz, R.K., Devoid, S., Dsiz, T., et al. (2012) SEED servers: high performance access to the SEED genomes, annotations and metabolic models. PLoS ONE 7, e48053.

[5] Barona-Gomez, F., Wong, U., Giannakopulos, A.E., Derrick, P., Challis, G.L. (2004) Identification of a cluster of genes that detects desferioxanthine biosynthesis in Streptomyces coelicolor M145. J. Am. Chem. Soc. 126, 16282-16283.

[6] Boncompagni, E., Osteras, M., Poggi, M.C., le Rudulier, D. (1999) Occurrence of choline and glycine betaine uptake and metabolism in the family Rhizobiaceae and their roles in osmoprotection. Appl. Environ. Microbiol. 65, 2072-2077.

[7] Boncompagni, E., Dupont, L., Osteras, M., Lamport, A., Poggi, M.C., le Rudulier, D. (2000) Characterization of a Sinorhizobiun meliloti, ATP binding histidine transporter also involved in betaine and proline uptake. J. Bacteriol. 332, 3717-3725.

[8] Busarakam, K., Bull, A.T., Girard, G., Labeda, D.P., van Wezel, G.P., Goodfellow, M. (2014) Streptomyces leeuwenhoekii sp. nov., the producer of chaxalactins and chaxamycins, forms a distinct branch in Streptomyces gene trees. Antonie van Leeuwenhoek 105, 849-861.

[9] Cáceres, L., Gomez-Silva, B., Garro, X.B., Rodriguez, V., Monardez, V., McKay, C.P. (2007) Relative humidity patterns and fog water precipitation in the Atacama Desert and biological implications. J. Geophys. Res. 112, G04814. 
[10] Carro, L., Spröer, C., Alonso, P., Trujillo, M.E. (2012) Diversity of Micromonospora strains isolated from nitrogen fixing nodules and rhizosphere of Pisum sativum analyzed by multilocus sequence analysis. Syst. Appl. Microbiol. 35, 73-80.

[11] Dobbek, H., Gremer, L., Meyer, O., Huber, R. 2006 CO dehydrogenase. Molybdenum/tungsten. In: Handbook of Metalloproteins, John Wiley \& Sons, pp. , 183, http://dx.doi.org/10.1002/0470028367.met (Published online: 15 April 2006).

[12] Essoussi, I., Ghodhbane-Gtari, F., Amairi, H., Sghaier, H., Jaouani, A., Brusetti, L., Daffonchio, D., Boudabous, A., Gtari, M. (2010) Esterase as an enzyme signature of Geodermatophilus adaptability to Sahara desert stones and monuments. J. Appl. Microbiol. 108, 1723-1732.

[13] Etchegaray, J.P., Inouye, M. (1999) CspA, CspB and CspG, major cold shock proteins of Escherichia coli, are induced at low temperature under conditions that completely block protein synthesis. J. Bacteriol. 181, 1827-1830.

[14] Felsenstein, J. (1981) Evolutionary trees from DNA sequences: a maximum likelihood approach. J. Mol. Evol. 17, 368-376.

[15] Felsenstein, J. (1985) Confidence limits on phylogenies: an approach using the bootstrap. Evolution 39, 383-391.

[16] Fitch, W.M. (1971) Toward defining the course of evolution: minimum change for a specific tree topology. Syst. Zool. 20, 406-416.

[17] Gomez-Escribano, J.P., Castro, J.F., Razmilic, V., Chandra, G., Andrews, B., Asenjo, J.A., Bibb, M.J. (2015) The Streptomyces leeuwenhoekii genome de novo sequencing and assembly in single contigs of the chromosome circular plasmid pLSE1 and linear plasmid pLSE2. BMC Genom. 16, 485.

[18] Goosen, N., Moolenaar, G.F. (2008) Repair of UV damage in bacteria. DNA Repair 7, 353-379.

[19] Gtari, M., Essoussi, I., Maaoui, R., Sghaier, H., Boujmil, R., et al. (2012) Contrasted resistance of stone dwelling Geodermatophilaceae species to stresses known to give rise to reactive oxygen species. FEMS Microbiol. Ecol. 80, 566-577.

[20] Hasegawa, T., Takizawa, M., Tamida, S. (1983) A rapid analysis for chemical grouping of aerobic actinomycetes. J. Gen. Appl. Microbiol. 2, 319-322.

[21] Hayakawa, M., Nonomura, H. (1987) Humic acid-vitamin agar, a new medium for the selective isolation of soil actinomycetes. J. Ferm. Technol. 65, 501-509.

[22] Hickson, I.D. (2003) Rec Q helicases: caretakers of the genome. Nat. Rev. Cancer 3, 169-178.

[23] Jones, K. (1949) Fresh isolates of actinomycetes in which the presence of the sporogenous aerial mycelia is a fluctuating characteristic. J. Bacteriol. 57, $141-145$.

[24] Kang, J., Blaser, M.J. (2006) UvRD helicas suppresses recombination and DNAdamaged-deduced deletions. J. Bacteriol. 188, 5050-5059.

[25] Kappes, R.M., Kempf, B., Knelp, S., Boch, J., Gade, J., Meier-Wagner, J., Bremer, E. (1999) Two evolutionarily closely related ABC transporters mediate the uptake of choline for synthesis of the osmoprotectant glycine betaine in Bacillus subtilis. Mol. Microbiol. 32, 203-216.

[26] Kim, O.S., Cho, Y.J., Lee, K., Yoon, S.H., Kim, M., Na, H., Park, S.C., Jeon, Y.S., Lee, J.H., Yi, H., Won, S., Chun, J. (2012) Introducing EzTaxon-e: a prokaryotic $16 S$ rRNA gene sequence database with phylotypes that represent uncultured species. Int. J. Syst. Evol. Microbiol. 62, 716-721.

[27] Konstantinidis, K.T., Tiedje, J.M. (2005) Genomic insights that advance the species definition for prokaryotes. Proc. Natl. Acad. Sci. U. S. A. 102, 2567-2572.

[28] Konstantinidis, K.T., Ramette, A., Tiedje, J.M. (2006) The bacterial species definition in the genomic era. Philos. Trans. R. Soc. Lond. B 361, 1929-1940.

[29] Li, J.S.B.L.V.T., Dong, C., Yang, J.F., Liang, W.D. (2011) Transcriptome analysis of adaptive heat shock response of Streptococcus thermophilus. PLoS ONE 6, e25777.

[30] Lorite, M.J., Tachil, J., Sanjuan, J., Meyer, O., Bedmar, E.J. (2000) Carbon monoxide dehydrogenase activity in Bradyrhizobium japonicum. Appl. Environ. Microbiol. 66, 1871-1876.

[31] Lucchetti-Miganeh, C., Burrowes, E., Bayesse, C., Ermel, E. (2008) The posttranscriptional regulator CsrA plays a central role in the adaptation of bacterial pathogens to different stages of infection in animal hosts. Microbiology 154, $16-29$.

[32] Mackenzie, C., Chidambarem, M., Sodergren, E.J., Kaplan, S., Weinstock, G.M. (1995) DNA repair mutants of Rhodobacter sphaeroides. J. Bacteriol. 177, 3027-3035.

[33] Mandon, K., Osteras, M., Boncompagni, E., Trinchant, J.C., Spennato, G., Poggi, M.C., le Rudulier, D. (2003) The Sinorhizobium meliloti glycine betaine biosynthetic genes ICBA are induced by choline and highly expressed in bacteroids. Mol. Plant Microb. Interact. I 16, 709-719.

[34] Manthei, K.A., Hill, M.C., Burke, J.E., Butcher, S.E., Keck, J.L. (2015) Structural mechanisms of DNA binding and unwinding in bacterial Rec Q helicases. Proc. Natl. Acad. Sci. U. S. A. 112, 4292-4297.

[35] Medema, M.H., Blin, K., Cimermancic, P., de Jager, V., Zakrzewski, P., Fischbach, M.A., Weber, T., Takano, E., Breitling, R. (2011) AntiSMASH: rapid identification, annotation and analyses of secondary metabolic biosynthesis gene clusters in bacterial and fungal genome sequences. Nucleic Acids Res. 39, W339-W346.

[36] Meier-Kolthoff, G.P., Auch, A.F., Klenk, H.P., Göker, M. (2013) Genome sequence based species delimitations with constant intervals and improved distance functions. BMC Bioinform. 14, 60.

[37] Mevs, U., Stackebrandt, E., Schumann, P., Gallikowski, C.A., Hirsch, P. (2000) Modestobacter multiseptatus sp. nov., a budding actinomycete from soils of the Asgard Range (Transantarctic Mountains). Int. J. Syst. Evol. Microbiol. 50, 337-346.

[38] Minnikin, D.E., O’Donnell, A.G., Goodfellow, M., Alderson, G., Athalye, M., Schaal, A., Parlett, J.H. (1984) An integrated procedure for the extraction of bacterial isoprenoid quinones and polar lipids. J. Microb. Methods 2, 233-241.
[39] Murray, P.R., Baron, E.J., Phaller, M.A., Ternover, J.C., Yolkken, R.J. 1999 Manual of Clinical Microbiology, 7th ed., ASM Press, Washington, DC.

[40] Nau-Wagner, G., Opper, D., Rolbetzk, A., Boch, J., Kempf, B., Hoffmann, T., Bremer, E. (2012) Genetic control of osmoadaptive glycine betaine synthesis in Bacillus subtilis through the choline-sensing and glycine-betaine-responsive GbsR repressor. J. Bacteriol. 194, 2703-2714.

[41] Normand, P. (2006) Geodermatophilaceae fam. nov., a formal description. Int. J. Syst. Evol. Microbiol. 56, 2277-2278.

[42] Normand, P., Benson, D.R. (2012) Family IV. Geodermatophilaceae 2006, 2277VP (Effective publication: Normand, Orso, Cournoyer, Jeannin, Chapelon, Dawson, Evtuschenko and Misra, 1996, 8), in: Goodfellow, M., Kämpfer, P., Busse, H.-J. Trujillo, M.E., Suzuki, K.-I., Ludwig, W., Whitman, W.B. (Eds.), Bergey’s Manual of Systematic Bacteriology, Part A, vol. 5, 2nd ed., Springer, New York, p. 528.

[43] Normand, P., Benson, D.R. (2012) Genus III. Modestobacter Mevs, Stackebrandt Schumann, Gallikovski and Hirsch 2000, 344AP emend Reddy, Potrafka and Garcia-Pichel 2007, 2018L. In: New York, in: Goodfellow, M., Kämpfer, P., Busse, H.-J., Trujillo, M.E., Suzuki, K.-I., Ludwig, W., Whitman, W.B. (Eds.), Bergey's Manual of Systematic Bacteriology, Part A, vol. 5, 2nd ed., Springer, pp. 536-539.

[44] Normand, P., Daffonchio, D., Gtari, M. (2014) Family Geodermatophilaceae. In: Rosenberg, E (Ed.), The Prokaryotes - Actinobacteria, Springer-Verlag.

[45] Normand, P., Gury, J., Pujic, P., Chouaia, B., Crott, E., Brusetti, L., Daffonchio, D., Vacheri, B., Barbe, V., Medigie, C., Calteau, A., Ghodhbane-Gtari, Essoussi, I., Nouioui, I., Abbassi-Ghozzi, I., Gtari, M. (2012) Genome sequence of radiation-resistant Modestobacter marinus strain BC501, a representative actinobacterium that thrives on calcareous stone surfaces. J. Bacteriol. 194, 4773-4774

[46] Osteras, M., Boncompagni, E., Vincent, M., Poggi, M.C., Le Rudulier, D. (1998) Presence of a gene encoding choline sulfatase in Sinorhizobium meliloti bet operon: choline-O-sulfate is metabolized into glycine betaine. Proc. Natl. Acad. Sci. U. S. A. 95, 11394-11399.

[47] Purdham, P.W., Bradford, P.G., Tamura, K., Kumar, S. (2000) Single column discrepancy and dynamic max-mini optimizations for quickly finding the most parsimonious evolutionary trees. Bioinformatics 16, 140-151.

[48] Qin, S., Bian, G.-K., Zhang, Y.-J., Ying, K., Cao, C.-L., Liu, C.-H., Dai, C.-C., Jiang, J.H. (2013) Modestobacter roseus sp. nov., an endophytic actinomycete isolated from the coastal halophyte Salicornia europea Linn, and emended description of the genus Modestobacter. Int. J. Syst. Microbiol. 63, 2197-2202.

[49] Rasmussen, J.J., Vegge, C.S., Frokiaer, H., Howlett, R., Krogfelt, K.A., Kelly, D.J. Ingmer, H. (2013) Campylobacter jejuni carbon starvation protein A (Cst A) is involved in peptide utilization motility and agglutination and has a role in stimulation of dendritic cells. J. Med. Microbiol. 62, 1135-1143.

[50] Reddy, G.S.N., Potrafka, R.M., Garcia-Pichel, F. (2007) Modestobacter versicolor sp. nov., an actinobacterium from biological soil crusts that produces melanins under oligotrophy, with emended descriptions of the genus Modestobacter and Modestobacter multiseptatus Mevs et al. 2000. Int. J. Syst. Evol. Microbiol. 57, 2000-2014.

[51] Reina-Bueno, M., Argandona, M., Nieto, J.J., Hidalgo-Garciam, A., IglesiasGuerra, F., Delgado, M., Vargas, C. (2010) Role of trehalose in heat and desiccation tolerance in the soil bacterium Rhizobium etli. BMC Microbiol. 12, 207-.

[52] Richter, M., Rosselló-Móra, R. (2009) Shifting the genomic gold standard for the prokaryotic species definition. Proc. Natl. Acad. Sci. U. S. A. 106, 19126-19131.

[53] Romero, T. (1998) Global regulation by the small RNA-binding protein CsrA and the non-coding RNA molecule csrB. Mol. Microbiol. 29, 1321-1330.

[54] Romero, T., Gong, M., Liu, M.Y., Brun-Zinkernagel, A.M. (1993) Identification and molecular characterization of csrA, a pleiotrophic gene from Escherichia coli that affects glycogen biosynthesis, gluconeogenesis, cell size and surface properties. J. Bacteriol. 175, 4744-4755.

[55] Saitou, N., Nei, M. (1987) The neighbour-joining method: a new method for constructing phylogenetic trees. Mol. Biol. Evol. 4, 406-425.

[56] Sangal, V., Nieminen, L., Tucker, M.P., Hoskisson, P.A. (2014) Revolutionizing prokaryotic systematics through next generation sequencing. Methods Microbiol. 41, 75-101.

[57] Sasser, M. 1990 Identification of Bacteria by Gas Chromatography of Cellular Fatty Acids. MIDI Technol. Note 101, MIDI Inc., Newark.

[58] Schulze, J.E., Matin, A. (1991) Molecular and functional characterization of a carbon starvation gene of Escherichia coli. J. Mol. Biol. 218, 129-140.

[59] Sen, A., Daubin, E., Abbro, D., Gifford, I., Berry, A.M., Normand, P. (2014) Phylogeny of the class Actinobacteria revisited in light of complete genomes. The orders 'Frankiales' and Micrococcales should be split into coherent entities: proposal of Frankiales ord. nov., Geodermatophilales ord. nov, Acidothermales ord. nov. and Nakamurellales ord. nov. Int J Syst. Evol. Microbiol. 64, 3821-3832.

[60] Sentausa, E., Fournier, P.E. (2013) Advantages and limitations of genomics in prokaryotic taxonomy. Chem. Microbiol. Infect. 19, 790-795.

[61] Sghaier, H., Hezbri, K., Ghodhbane-Gtari, F., Pujic, P., Sen, A., Daffonchio, D. Boudabous, A., Tisa, L.S., Klenk, H.-P., Armengaud, J., Normand, P., Gtari, M. (2015) Stone-dwelling actinobacteria Blastococcus saxobsidens, Modestobacter marinus and Geodermatophilus obscurus proteogenomes. ISME J., 1-9.

[62] Shirling, E.B., Gottlieb, D. (1966) Methods for characterization of Streptomyces species. Int. J. Syst. Bacteriol. 16, 313-340.

[63] Stackebrandt, E., Rainey, F.A., Ward-Rainey, N. (1997) Proposal for a new hierarchic classification system, Actinobacteria classis nov. Int. J. Syst. Bactreiol. 47, 479-491.

[64] Staneck, J.L., Roberts, G.D. (1974) Simplified approach to the identification of aerobic actinomycetes by thin-layer chromatography. Appl. Microbiol. 28, $226-231$. 
[65] Tamura, K., Stecker, C., Peterson, D., Filipsk, A., Kumar, S. (2013) MEGA 6: molecular evolutionary genetics analysis version 6. Mol. Biol. Evol. 30, 2725-2729.

[66] Thompson, J.D., Gilson, D.J., Plewniak, F., Jeanmougin, F., Higgins, D.J. (1997) The CLUSTAL X windows interface flexible strategies for multiple sequence alignments aided by quality analysis tools. Nucleic Acids Res. 25, 4876-4882.

[67] Tierrafria, V.H., Ramos-Aboites, H.E. Gosset, G., Barona-Gomez, F. (2011) Disruption of the siderophore binding DesE receptor gene in Streptomyces coelicolor A3 (2) results in impaired growth in spite of multiple iron-siderophise transport systems. Microb. Biotechnol. 4, 275-285.

[68] Trujillo, M.E., Alonso-Vega, P., Rodriguez, R., Carro, L., Cerda, E., Alonso, P., Martinez-Molina, E. (2010) The genus Micromonospora is widespread in legume root nodules: the example of Lupinus angustifolius. ISME J. 4, 1265-1281.

[69] Trujillo, M., Goodfellow, M., Busarakam, K., Riesco, R. (2015) Modestobacter lapidis sp. nov. and Modestobacter muralis sp. nov., isolated from a deteriorated sandstone historic building in Salamanca, Spain. Antonie van Leeuwenhoek 108, 311-320.

[70] Urzi, C., Brusetti, P., Salamone, C., Sorlini, F., Stackebrandt, E., Daffonchio, D. (2001) Biodiversity of Geodermatophilaceae isolated from altered stones and monuments in the Mediterranean basin. Environ. Microbiol. 3, 471-479.
[71] Versalovic, J., Schneider, M., De Bruijn, F.J., Lupski, J.R. (1994) Genomic fingerprinting of bacteria using repetitive sequence-based polymerase chain reaction. Methods Mol. Cell. Biol. 5, 25-40.

[72] Vickers, J.C., Williams, S.T. (1987) An assessment of plate inoculation methods for the enumeration and isolation of soil streptomycetes. Microb. Lett. 3, 113-117.

[73] Wargo, M.J., Szwergold, B.S., Hogan, D.A. (2008) Identification of two gene clusters and a transcriptional regulator required for Pseudomonas aeruginosa glycine betaine catabolism. J. Bacteriol. 190, 2690-2699.

[74] Wayne,.L.G., Brenner, D.J., Colwell, R.R., Grimont, P.A.D., Kandler, O., et al. (1987) Report of the ad hoc committee on reconciliation of approaches to bacterial systematics. Int. J. Syst. Bacteriol. 37, 463-464.

[75] Xiao, J., Luo, Y., Yu, J., Xie, J. (2011) Modestobacter marinus sp. nov., a psychrotolerant actinobacterium from deep-sea, and emended description of the genus Modestobacter. Int. J. Syst. Evol. Microbiol. 61, 1704-17010.

[76] Zakharova, O.S., Zenova, G.M., Zvyagintsev, D.G. (2003) Some approaches to the selective isolation of actinomycetes of the genus Actinomadura from soil. Microbiology 72, 110-113.

[77] Zerbino, D.R., Birney, E. (2008) Velvet: algorithms for de novo short read assembly using Bruijin graphs. Genome Res. 18, 821-829. 